\title{
Multilayer Membranes Based on Sulfonated Poly(Ether Ether Ketone) and Poly(Vinyl Alcohol) for Direct Methanol Membrane Fuel Cells
}

\author{
Tao Yang*, Suo Xin Zhang, Yong Gao, Feng Cheng Ji and Tang Wei Liu \\ School of Chemical Engineering, Huaihai Institute of Technology, Lianyungang Jiangsu 222005, China
}

\begin{abstract}
Much work has been conducted on the substitutes for Nafion as proton exchange membrane materials. Some researches are focused on the heterogeneous multilayered membranes reported by R. Jiang [J. Electrochem. Soc. 153 (2006) A1554], B. Yang [Electrochem. Commun. 6 (2004) 231] and S. Ren [J. Membr. Sci. 247 (2005) 59]. However, just as the dependence of methanol crossover upon the layer with the lowest permeability, the proton transfer ability is major confined by the layer with the poorest conductivity. Moreover, various swelling ratio and contractibility of sub-layers will make the hidden problems of separation between catalyst layer and proton exchange membrane become more obvious. We present here a multilayered membranes containing five thin layers of sulfonated poly(ether ether ketone)(SPEEK) and five thin layers of poly(vinyl alcohol)(PVA). SPEEK layers and PVA layers were located alternatively in the composite membrane. The swelling behaviors of PVA layer are restrained by both sideward SPEEK layers. Methanol crossover is efficiently alleviated piece by piece without visible proton conductivity loss. The preliminary investigation in DMFC suggests its promising application as resisting methanol and proton exchange membrane.
\end{abstract}

Keyword: Multilayered membrane, Double-layer membrane, Methanol crossover, DMFC.

\section{INTRODUCTION}

Direct methanol fuel cells (DMFC) are attractive for transportation and portable application as they can offer important advantages such as high efficiency, compact structure and ease in refueling. Many breakthroughs in DMFC technology are obtained and some prototype fuel cells have been unveiled by now. However, several problems still need to be overcome before a general usage of the DMFC technology could be achieved. One of the major obstacles is the methanol crossover from the anode to the cathode through the typical Nafion membranes. This problem can be relieved by applying the dilute methanol. However, the dilute methanol can aggravate the drainage task of cathode. On the other hand, high methanol concentration is attractive to obtain high energy density. Therefore, the proton exchange membrane with low methanol permeation is particularly urgent for practical application.

In this regard, much work has been devoted to the development of fluorine-free alternative such as sulfonated poly(ether sulfones) $[1,2]$, sulfonated poly(arylene ether)s [3], sulfonated poly ( $p$-phenylene) $[4,5]$, sulfonated polyimide [6,7], sulfonated poly(arylene ether ketones) $[8,9,10]$ and sulfonated aromatic poly(ether ether ketone) [11-14]. Among these membrane materials, SPEEK membranes are promising as they can offer adjustable proton conductivity $[15,16]$, excellent chemical and thermal stability [17]. Moreover, SPEEK membranes show lower methanol permeation than Nafion membrane due to their narrower and more branched hydrophilic channels [18]. Proton conductivity of this membrane is mainly dependent on sulfonation

*Address correspondence to this author at the School of Chemical Engineering, Huaihai Institute of Technology, Lianyungang Jiangsu 222005, China; E-mail: yangtao_hit@163.com degree (DS) [19-20]. The DS of SPEEK can be adjusted by sulfonation time, temperature and concentration of sulfuric acid conveniently [21-24]. However, the introduction of $\mathrm{SO}_{3}$ groups can destroy the ordered structure of SPEEK molecular and promote the decomposition of SPEEK [18]. Moreover, SPEEK shows an increase in methanol crossover upon DS, which was induced by the severe membrane swelling in the methanol solution [25]. To maintain lower methanol permeability and suitable stability at high DS, many investigations have been conducted on the blend membranes based on SPEEK and crosslink additives such as poly(ether sulfone), poly(amide imide), polysulfone and poly(benzimidazole) [26-29]. However, the interactions between SPEEK molecules and additives are complex and indistinct, which might destroy the proton transfer channels and affect the cell performance negatively.

Recent years, a few researches have been conducted on the heterogeneous membranes such as multilayered membrane $[25,30,31]$, which can offer satisfactory performance. Ren immersed SPEEK into Nafion containing casting solution to prepared Nafion-SPEEK-Nafion composite membranes. In Jiang's work [25], a thin layer of SPEEK with a lower DS (41\%) was used as the central methanol barrier layer; higher DS $(60 \%)$ SPEEK layers were applied on the two outer surfaces as the conductive layers. Yang [30] fabricated a multilayered membrane containing a thin central layer of SPEEK and two outer layers of recast Nafion. The investigation on the multilayered membranes suggests their promising application in DMFC. However, the self-governed characteristic of each layer should not be neglected. The multilayered membrane reported before contains only three layers, the thickness of each layers is ranging from 10 100 $\mu_{\mathrm{m}}$; each layers becomes one independent phase and presents the distinct characteristic of itself. Fox example, the various swelling ratio and mechanical strength of each layer 
make it difficult to maintain the tight contact among each other. Therefore, the separations in practical application might be an anxious problem. Moreover, the proton conductivity of the multilayered membrane might be restricted by the layer with poor proton transfer ability just as the major dependence of methanol crossover upon the layer with low methanol permeability $[25,30,31]$. In view of these problems, we present here a multilayered membrane containing five thin SPEEK layers and five thin PVA layers, above two kinds of layers were located alternatively. The thickness of each layer is about several microns. The thin layers of PVA are expected to block the methanol permeation piece by piece. The thin layers of SPEEK offer good mechanical strength and low swelling ratio. The multilayered membranes could thus alleviate the methanol crossover problem while offering good mechanical strength and cell performance.

\section{EXPERIMENTAL}

The details on sulfonation of poly(ether ether ketone) have been report elsewhere [12]. Based on our previous study and reports by Yang [30], SPEEK membrane with a sulfonation level above $50 \%$ could obtain reasonable proton conductivity and suitable mechanical properties. Hereby, a DS of $55 \%$ was used in this study to demonstrate the concept. The homogenous SPEEK solution (10\%, dissolved in DMSO) and PVA (10 \%, $\mathrm{H}_{3} \mathrm{PO}_{4} 2 \%$, dissolved in DMSO, solution was obtained beforehand by thermal dissolving. The multilayered membrane was fabricated by the sample casting method repeatedly. $1 \mathrm{~mL}$ SPEEK solution was firstly dropped on the tailor-made plate (diameter: $75 \mathrm{~mm}$ ) and evaporated at $60{ }^{\circ} \mathrm{C} .1 \mathrm{~mL}$ PVA solution was then dropped onto the as formed SPEEK membrane and evaporated at 60 ${ }^{\circ} \mathrm{C}$. Subsequently, $1 \mathrm{~mL}$ SPEEK solution was again dropped on the PVA surface and evaporated at $60{ }^{\circ} \mathrm{C}$. The above process was repeated until five SPEEK layers and five PVA layers were obtained alternately. With the aim of comparison, double-layer membrane and blend membrane were fabricated too. Double-layer membrane was fabricated by dropping $5 \mathrm{~mL}$ SPEEK solution on the customized plate and dried at $60{ }^{\circ} \mathrm{C}, 5 \mathrm{~mL}$ PVA solution was then dropped onto the SPEEK surface and evaporated at $60{ }^{\circ} \mathrm{C}$. Blend membrane was formed by mixing $5 \mathrm{~mL}$ SPEEK solution and 5 $\mathrm{mL}$ PVA solution homogenously, the mixed solution was then casted onto the tailor-made plate and dried at $60{ }^{\circ} \mathrm{C}$. The three composite membranes above was finally dried under vacuum at $80{ }^{\circ} \mathrm{C}$ for $12 \mathrm{~h}$ and $110{ }^{\circ} \mathrm{C}$ for $3 \mathrm{~h}$. The as formed multilayered membrane, double-layer membrane and blend membrane are designated, respectively, as MM, DM and BM.

Liquid uptake of the membranes in water and $10 \mathrm{M}$ methanol solution was calculated by determinating the change in weight and dimensions under dry and wet status [32]. Ionic exchange capacity was obtained by classical titration method [12]. Methanol permeability was measured using a homemade glass diffusion cell. The structure and the process were similar to the report [32]. The proton conductivity was measured by AC impedance spectroscopy over a frequency range of $1-10^{6} \mathrm{~Hz}$. The performances of the cells with MM, DM and BM membranes were compared. The above experiments were all carried at $80{ }^{\circ} \mathrm{C}$.

\section{RESULTS AND DISCUSSION}

\subsection{Swelling Behavior in Water and $10 \mathrm{M}$ Methanol So- lution}

Table 1 summarizes the water uptake and swelling ratio of the three composite membranes at $80{ }^{\circ} \mathrm{C}$. The swelling ratio in the direction of plane is far lower than that in thickness direction, which might be beneficial to the practical DMFC. In DMFC applications, thickness swelling might reinforce the contact between current collectors and membrane electrolyte assembly. In contrary, the swelling in plane can loosen the contact between electrolyte membrane and catalyst resulting in the increase in resistance of MEA and separations in the later applications. The water uptake for the MM membrane is lower than those of DM and BM membranes. Especially, the dimensional stability of MM membrane is much higher than the other two membranes. The higher swelling behavior of thin PVA layers was restrained by both sideward SPEEK layers. DM membrane shows the highest uptake and swelling ratio due to the higher uptake of PVA layer. BM membrane shows the middle swelling behavior on account of some interaction between SPEEK and PVA molecules, which will be discussed in other paper. The similar results in $10 \mathrm{M}$ methanol solution are presented in Table 2.

Table 1. Swelling Behavior in Water

\begin{tabular}{|c|c|c|c|}
\hline Membrane Samples & Uptake (\%) & Thickness Swelling (\%) & Planar Swelling (\%) \\
\hline \hline Multilayer membrane (MM) & 30.5 & 28.4 & 5.3 \\
\hline Double-layer membrane (DM) & 76.2 & 67.1 & 16.8 \\
\hline Blend Membrane (BM) & 46.8 & 30.2 & 12.4 \\
\hline
\end{tabular}

Table 2. Swelling Behavior in $10 \mathrm{M}$ Methanol

\begin{tabular}{|c|c|c|c|}
\hline Membrane Samples & Uptake (\%) & Thickness Swelling (\%) & Planar Swelling (\%) \\
\hline \hline Multilayer membrane (MM) & 15.2 & 11.1 & 3.3 \\
\hline Double-layer membrane (DM) & 40.6 & 28.8 & 12.4 \\
\hline Blend Membrane (BM) & 28.7 & 19.5 & 7.1 \\
\hline
\end{tabular}


Table 3. IEC, Proton Conductivity and Methanol Permeability

\begin{tabular}{|c|c|c|c|}
\hline Membrane Samples & IEC $\left(\mathbf{m m o l ~ \mathbf { g } ^ { - 1 } )}\right.$ & Proton Conductivity $\left(\mathbf{S ~ c m}^{-1}\right)$ & ${\text { Methanol Permeability }\left(\mathbf{c m}^{2} \mathbf{s}^{-1}\right)}$ \\
\hline \hline Multilayer membrane (MM) & 1.01 & $5.5 \times 10^{-2}$ & $3.0 \times 10^{-6}$ \\
\hline Double-layer membrane (DM) & 0.92 & $1.7 \times 10^{-2}$ & $5.5 \times 10^{-6}$ \\
\hline Blend Membrane (BM) & 0.35 & $4.4 \times 10^{-3}$ & $2.9 \times 10^{-6}$ \\
\hline
\end{tabular}

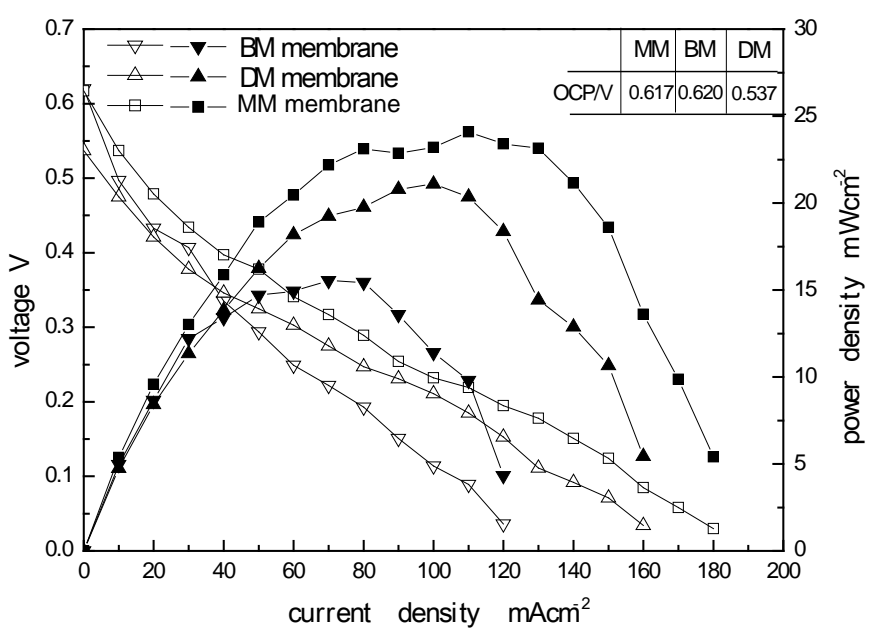

\begin{tabular}{|c|c|c|c|c|c|c|}
\hline \multirow{2}{*}{$\begin{array}{l}\text { Current density } \\
\mathrm{mA} \mathrm{cm}\end{array}$} & \multicolumn{3}{|c|}{ Voltage $V$} & \multicolumn{3}{|c|}{ Power density $\mathrm{mW} \mathrm{cm}^{-2}$} \\
\hline & BM & DM & MM & $\mathbf{B M}$ & DM & MM \\
\hline 0 & 0.62 & 0.537 & 0.617 & 0 & 0 & 0 \\
\hline 20 & 0.433 & 0.421 & 0.479 & 8.66 & 8.42 & 9.58 \\
\hline 30 & 0.407 & 0.378 & 0.434 & 12.21 & 11.34 & 13.02 \\
\hline 60 & 0.249 & 0.303 & 0.341 & 14.94 & 18.18 & 20.46 \\
\hline 70 & 0.222 & 0.275 & 0.317 & 15.54 & 19.25 & 22.19 \\
\hline 80 & 0.193 & 0.247 & 0.289 & 15.44 & 19.76 & 23.12 \\
\hline 90 & 0.151 & 0.231 & 0.254 & 13.59 & 20.79 & 22.86 \\
\hline 140 & & 0.092 & 0.151 & & 12.88 & 21.14 \\
\hline 150 & & 0.071 & 0.124 & & 10.65 & 18.6 \\
\hline 160 & & 0.034 & 0.085 & & 5.44 & 13.6 \\
\hline 170 & & & 0.058 & & & 9.86 \\
\hline 180 & & & 0.03 & & & 5.4 \\
\hline
\end{tabular}

\begin{tabular}{|c|c|c|c|}
\hline & MM & BM & DM \\
\hline \hline OCP/V & 0.617 & 0.620 & 0.537 \\
\hline
\end{tabular}

Fig. (1). Polarization curves of cells with different membranes.

\subsection{IEC, Proton Conductivity and Methanol Permeabil- ity}

Ionic exchange capacity (IEC) is usually considered to correspond to the proton transfer property in homogenous proton exchange membrane. However, it is only a referenced factor offering contributions to the proton conductivity in multilayered and double-layer membranes. In heterogenous membranes, the proton conductivity of the double-layer membrane is restricted by the sub-layer with larger proton 
resistance. IEC, proton conductivity and methanol crossover results are shown in Table 3 . Compared to DM membrane, MM membrane achieved more than three times proton conductivity in despite of the similar IEC value. The proton transfer ability of DM membrane was confined by the large block of PVA layer. BM presents the lowest IEC and proton conductivity due to some interaction between SPEEK and PVA molecule.

MM membrane gives equivalent methanol permeability to that of BM. In our test, it also means that the methanol resistance piece by piece in multilayered membrane is much efficient than the double-layer membrane.

\subsection{Open Circuit Potential and Polarization of the Cells}

Fig. (1) compares the open circuit potential (OCP) and polarization curves of cells assembled with MM, DM and BM membranes. BM membrane exhibits larger polarization losses than the MM membrane due to the poor proton conductivity. The inset-table shows the similar OCP value of $\mathrm{BM}$ and $\mathrm{MM}$ membrane. DM membrane presents lower OCP than the other membranes due to the slightly larger methanol permeability. However, DM membrane gives better performance than BM membrane. The results in Fig. (1) suggest the promising application of multilayered membrane in DMFC.

\section{CONCLUSION}

We have demonstrated a multilayered membrane concept to alleviate methanol crossover and maintain high proton conductivity. This concept was based on the performance difference between homogenous membrane and heterogenous membrane reported in $[25,30,31]$. Multilayered membranes containing five thin layers of SPEEK are found to significantly reduce the swelling ratio and maintain high proton transfer ability; five thin layers of PVA are determined to block methanol crossover piece by piece efficiently. We believe that this multilayered approach to membrane fabrication is a promising attempt to develop the good proton exchange membrane. Further investigations on longterm stability in DMFC, the effect of thickness and layers number are currently underway in our laboratory. Multilayered membranes based on other materials will also be studied in our following research.

\section{ACKNOWLEDGEMENT}

The authors gratefully acknowledge the financial support of Huaihai Institute of Technology of China through Project Nos. KQ07097 and KX07048.

\section{REFERENCE}

[1] Wang, F.; Hickner, M.; Kim, Y.S.; Zawodzinski, T.A.; McGrath, J.E. Direct polymerization of sulfonated poly(arylene ether sulfone) random (statistical) copolymers: candidates for new proton exchange membranes. J. Membr. Sci., 2002, 197 (1-2), 231-42.

[2] Li, Y.; Wang, F.; Yang, J.; Liu, D.; Roy, A.; Case, S.; Lesko, J.; McGrath, J.E. Synthesis and characterization of controlled molecular weight disulfonated poly(arylene ether sulfone) copolymers and their applications to proton exchange membranes. Polymer, 2006, $47,4210-17$

[3] Ghassemi, H.; McGrath, J.E.; Zawodzinski, T.A.; Jr. Multiblock sulfonated-fluorinated poly(arylene ether)s for a proton exchange membrane fuel cell. Polymer, 2006, 47, 4132-39.

[4] Chen, S.; Yin, Y.; Tanaka, K.; Kita, H.; Okamoto, K-I. Synthesis and properties of novel side-chain-sulfonated polyimides from bis [4-(4-aminophenoxy)-2-(3-sulfobenzoyl)] phenyl sulfone. Polymer, 2006, 47, 2660-69.

[5] Ghassemi, H.; McGrath, J.E. Synthesis and properties of new sulfonated poly ( $p$-phenylene) derivatives for proton exchange membranes. I. Polymer, 2004, 45, 5847-54.

[6] Genies, C.; Mercier, R.; Sillion, B.; Cornet, N.; Gebel, G.; Pineri, M. Soluble sulfonated naphthalenic polyimides as materials for proton exchange membranes. Polymer, 2001, 42, 359-73.

[7] Wu, S.; Qiu, Z.; Zhang, S.; Yang, X.; Yang, F.; Li, Z. The direct synthesis of wholly aromatic poly( $p$-phenylene)s bearing sulfobenzoyl side groups as proton exchange membranes. Polymer, 2006, 47, 6993-00.

[8] Xing, P.; Robertson, G.P.; Guiver, M.D.; Mikhailenko, S.D.; Kaliaguine, S. Sulfonated poly(aryl ether ketone)s containing the hexafluoroisopropylidene diphenyl moiety prepared by direct copolymerization, as Proton Exchange Membranes For Fuel Cell application. Macromolecules, 2004, 37, 7960 -67.

[9] Shang, X.; Li, X.; Xiao, M.; Meng, Y. Systhesis and characterization of sulfonated fluorine-containing poly(arylene ether ketone) for high temperature proton exchange membrane. Polymer, 2006, 47, 3807-13.

[10] Mikhailenko, S.D.; Wang, K.; Kaliaguine, S.; Xing, P.; Robertson, G.P.; Guiver, M.D. Proton conducting membranes based on crosslinked sulfonated poly(ether ether ketone) (SPEEK). J. Membr. Sci., 2004, 233, 93-99.

[11] Pasupathi, S.; Ji, S.; Bladergroen, B.J.; Linkov, V. High DMFC performance output using modified acid-base polymer blend. Int. J. Hydrogen Energy, 2008, 33, 3132-36.

[12] Park, J.-S.; Krishnan, P. A study on fabrication of sulfonated poly(ether ether ketone)-based membrane-electrode assemblies for polymer electrolyte membrane fuel cells. J. Power Sources, 2008, $178,642-50$.

[13] Mikhailenko, S. D; Zaidi, S. M.J.; Kaliaguine, S. Sulfonated polyether ether ketone based composite polymer electrolyte membranes. Catal. Today, 2001, 67, 225-36.

[14] Kobayashi, T.; Rikukawa, M.; Sanui, K.; Ogata, N. Protonconducting polymers derived from poly(ether-etherketone) and poly(4-phenoxybenzoyl-1,4-phenylene). Solid State Ionics, 1998, $106,219-25$

[15] Nunes, S.P.; Ruffmann, B. Inorganic modification of proton conductive polymer membranes for direct methanol fuel cells. $J$. Membr. Sci., 2002, 203, 215-25.

[16] Luo, Y.; Huo, R.; Jin, X.; Karasz, F.E. Thermal degradation of sulfonated poly(aryl ether ether ketone). J. Anal. Appl. Pyrolysis, 1995, 34, 229-42.

[17] Xing, P.; Robertson, G.P.; Guiver, M.D.; Mikhailenko, S.D.; Wang, K.; Kaliaguine S. Synthesis and characterization of sulfonated poly(ether ether ketone) for proton exchange membranes. J. Membr. Sci., 2004, 229, 95-06.

[18] Kreuer, K.D. On the development of proton conducting polymer membranes for hydrogen and methanol fuel cells. J. Membr. Sci., 2001, 185, 29-39.

[19] Rikukawa, M.; Sanui, K. Proton-conducting polymer electrolyte membranes based on hydrocarbon polymers. Prog. Polymer Sci., 2000, 25, 1463-502.

[20] Cui, W.; Kerres, J.; Eigenberger, G. Development and characterization of ion-exchange polymer blend membranes. Sep. Purif. Technol., 1998, 14, 145-54.

[21] Sambandam, S.; Ramani, V. SPEEK/functionalized silica composite membranes for polymer electrolyte fuel cells. J. Power Sources, 2007, 170, 259-67.

[22] Daoust, D.; Devaux, J. Godard, P. Mechanism and kinetics of poly(ether ether ketone) (PEEK) sulfonation in concentrated sulfuric acid at room temperaturePart 1. Qualitative comparison between polymer and monomer model compound sulfonation. Polym. Int., 2001, 50, 917-24.

[23] Zaidi, S.M.J.; Mikhailenko, S.D.; Robertson, G.P.; Guiver, M.D.; Kaliaguine, S. Proton conducting composite membranes from polyether ether ketone and heteropolyacids for fuel cell applications. J. Membr. Sci., 2000, 173, 17-34.

[24] Huang, R.Y.M.; Pinghai, S.; Burns, C.M. Sulfonation of poly(ether ether ketone)(PEEK): Kinetic study and characterization. J. Appl. Polym. Sci., 2001, 82, 2651-60.

[25] Jiang, R.; Kunz H.R.; Fentona, J.M. Multilayer structure membranes with sulfonated hydrocarbon methanol barrier for direct methanol fuel cells. J. Electrochem. Soc., 2006, 153, A1554-61. 
[26] Wilhelm, F.G.; Punt, I.G.M. Cation permeable membranes from blends of sulfonated poly(ether ether ketone) and poly(ether sulfone). J. Membr. Sci., 2002, 199, 167-76.

[27] Lufrano, F.; Squadrito, G. Sulfonated polysulfone as promising membranes for polymer electrolyte fuel cells. J. Appl. Polym. Sci., 2000, 77, 1250-56.

[28] Zhao, C.; Wang, Z.; Bi, D.; Lin, H.; Shao, K.; Fu, T.; Zhong, S. Blend membranes based on disulfonated poly(aryl ether ether ketone)s (SPEEK) and poly(amide imide) (PAI) for direct methanol fuel cell usages. Polymer, 2007, 48, 3090-97.

[29] Zhong, S.; Cui, X.; Cai, H.; Fu, T.; Shao, K.; Na, H. Crosslinked SPEEK/AMPS blend membranes with high proton conductivity and low methanol diffusion coefficient for DMFC applications. $J$. Power Sources, 2007, 168, 154-61.
[30] Yang, B.; Manthiram, A. Multilayered membranes with suppressed fuel crossover for direct methanol fuel cells. Electrochem. Commun., 2004, 6, 231-36.

[31] Ren, S.; Li, C.; Zhao, X.; Wu, Z.; Wang, S.; Sun, G.; Xin, Q.; Yang, X. Surface modification of sulfonated poly(ether ether ketone) membranes using Nafion solution for direct methanol fuel cells. J. Membr. Sci., 2005, 247, 59-63.

[32] Fu, T.; Zhao, C.; Zhong, S.; Zhang, G.; Shao, K.; Zhang, H.; Wang, J.; Na, H. SPEEK/epoxy resin composite membranes in situ polymerization for direct methanol fell cell usages. J. Power Source, 2007, 165, 708-16.

Received: October 31, 2008

Revised: December 01, 2008

Accepted: December 03, 2008

() Yang et al.; Licensee Bentham Open.

This is an open access article licensed under the terms of the Creative Commons Attribution Non-Commercial License (http://creativecommons.org/licenses/by-nc/3.0/) which permits unrestricted, non-commercial use, distribution and reproduction in any medium, provided the work is properly cited. 